\title{
Pengaruh Metode Pembelajaran Demonstrasi Terhadap Hasil Belajar Siswa Kelas X pada Mata Pelajaran Fiqih
}

\author{
Sarfiah, Restu Wibawa, Ary Purmadi \\ Program Studi Teknologi Pendidikan, Universitas Pendidikan Mandalika \\ *Corresponding Author. Email: fiahsar61@ gmail.com
}

\begin{abstract}
The purpose of this study was to determine the effect of the demonstration learning method on the learning outcomes of class X students in fiqh subjects at Madrasah Aliyah Hidayatullah Mataram in the 2020/2021 academic year. This research is a quantitative research using a two-group post test design type of experiment. The data collection technique in this study used the test as the main method with observation and documentation as a complementary method using the t-test formula. The population in this study amounted to 55 students. The sampling technique used in this research is random sampling with a total of 55 students. In accordance with the results obtained, the t-count is smaller than the t-table value $(1.714<2.101)$ which means Ho is accepted and $\mathrm{Ha}$ is rejected which reads: there is no effect of demonstration learning methods on the learning outcomes of class X students in fiqh subjects in Madrasahs Aliyah Hidayatullah Mataram, which is due to the limited time of class hours and there are still many students who do not concentrate and pay less attention to the teaching and learning process in the classroom.
\end{abstract}

\begin{abstract}
Abstrak: Tujuan penelitian ini adalah untuk mengetahui pengaruh metode pembelajaran demonstrasi terhadap hasil belajar siswa kelas X pada mata pelajaran fiqih di Madrasah Aliyah Hidayatullah Mataram Tahun Pelajaran 2020/2021. Penelitian ini merupakan penelitian kuantitatif dengan menggunakan jenis eksperimen two-group post test design. Teknik pengumpulan data dalam penelitian ini menggunakan tes sebagai metode pokok dengan observasi dan dokumentasi sebagai metode pelengkap dengan menggunakan rumus $t$-tes. Populasi dalam penelitian ini berjumlah 55 siswa. Teknik sampling yang digunakan dalam penelitian ini adalah Random Sampling dengan jumlah 55 siswa. Sesuai dengan hasil yang diperoleh t-hitung lebih kecil dari pada nilai t-tabel $(1.714<2.101)$ yang berarti Ho diterima dan Ha di tolak yang berbunyi: tidak ada pengaruh metode pembelajaran demonstrasi terhadap hasil belajar siswa kelas X pada mata pelajaran fiqih di Madrasah Aliyah Hidayatullah Mataram, yang dikarenakan keterbatasan waktu jam pelajaran serta masih banyaknya siswa yang tidak konsentrasi dan kurang memperhatikan pada saat berlangsungnya proses belajar mengajar didalam kelas.
\end{abstract}

How to Cite: Sarfiah, S., Wibawa, R., \& Purmadi, A. (2021). Pengaruh Metode Pembelajaran Demonstrasi Terhadap Hasil Belajar Siswa Kelas X pada Mata Pelajaran Fiqih. Jurnal Teknologi Pendidikan : Jurnal Penelitian dan Pengembangan Pembelajaran, 6(2), 201-207. doi:https://doi.org/10.33394/jtp.v6i2.4266

https://doi.org/10.33394/jtp.v6i2.4266

This is an open-access article under the CC-BY-SA License.

\section{Pendahuluan}

Pendidikan pada hakekatnya adalah usaha sadar untuk pengembangan kepribadian dan kemampuan seseorang baik melalui jalur sekolah maupun di luar jalur sekolah berlangsung seumur hidup. Menurut Maunah (2019) Pendidikan adalah segala pengalaman 
belajar yang berlangsung dalam segala lingkungan. Oleh karenanya, agar pendidikan dapat dimiliki oleh seluruh rakyat sesuai dengan kemampuan masing-masing individu, maka pendidikan adalah tanggung jawab keluarga, masyarakat dan pemerintah. Dengan demikian dapat dikatakan bahwa pendidikan merupakan bagian integral dalam pembangunan. Pembelajaran merupakan jantung dari proses pendidikan dalam situasi pendidikan. Karena itu merupakan kunci sukses untuk menggapai masa depan yang cerah, mempersiapkan generasi bangsa dengan wawasan ilmu pengetahuan yang tinggi, pada akhirnya diharapkan dapat berguna bagi bangsa, negara, dan agama. Pada tingkat mikro, pencapaian kualitas pembelajaran merupakan tanggung jawab profesional seorang guru, misalnya penciptaan pengalaman belajar yang bermakna bagi siswa dan fasilitas yang didapat siswa untuk mencapai hasil belajar yang maksimal. Faktor-faktor yang berpengaruh terhadap proses pembelajaran, baik secara eksternal maupan internal diidentifikasikan sebagai berikut. Faktor-faktor eksternal mencakup guru, materi, pola interaksi, media dan teknologi, situasi belajar dan sistem. Pembelajaran tidak lepas dengan metode, metode pembelajaran berfungsi sebagai salah satu cara yang digunakan guru dalam proses belajar mengajar. Ada beberapa metode pembelajaran yang sering digunakan atau telah dikenal misalnya metode ceramah, metode tanya jawab, metode diskusi, metode kerja kelompok, metode pemberian tugas, metode demonstrasi dan sebagainya. Oleh karena itu penggunaan metode pembelajaran yang tepat amat diperlukan dalam menumbuhkan kegiatan belajar bagi peserta didiknya.

Menurut Hartono dalam Ipung Yuwono (2017), rendahnya hasil belajar peserta didik secara umum disebabkan oleh metode mengajar yang digunakan guru. Metode merupakan salah satu faktor penting mengajar yang tidak lepas dari proses pembelajaran Pendidikan Agama Islam khususnya pada mata pelajaran fiqih. Ilmu tentang ibadah dalam khazanah keilmuan Islam dimuat dalam fiqih. Salah satu metode belajar mengajar yang dapat diterapkan untuk meningkatkan berbagai bentuk tingkah laku positif dan prestasi pada siswa adalah melalui metode demonstrasi. Metode demonstrasi selain menuntut guru menguasai kompetensi juga memberikan contoh kepada siswa tentang materi dan tujuan pembelajaran yang ingin dicapai.

Alasan peneliti menggunakan metode penelitian ini dikarenakan metode demonstrasi adalah metode jika dikaitkan dengan penyajian informasi dapat diartikan sebagai upaya peragaan atau pertunjukan tentang cara melakukan atau mengerjakan sesuatu. Dalam hal ini, siswa dapat mengamati, meneliti, melihat, memperhatikan pada apa yang dipertunjukkan oleh guru ketika proses mengajar berlangsung. Menurut Abuddin Nata (2009), dengan menggunakan metode demonstrasi pengajaran menjadi semakin jelas, mudah diingat dan dipahami, proses belajar lebih menarik, mendorong kreativitas siswa serta dapat meningkatkan hasil belajar. Berdasarkan uraian diatas yang menjadi permasalahan dalam penelitian ini adalah pengaruh metode demonstrasi terhadap hasil belajar siswa mata pelajaran fiqih di Madrasah Aliyah Hidayatullah Mataram.

\section{Metode Penelitian}

Rancangan dalam penelitian ini sesuai dengan penelitian eksperimen tipe praeksperiment Desain pola pre-test post-test satu kelompok (one group pretest-postest design) (Sugiyono 2013) 


\section{$\mathrm{O}_{1} \mathrm{X} \mathrm{O}_{2}$}

\section{Gambar 1. Rancangan Penelitian}

Populasi dalam penelitian ini adalah seluruh siswa kelas X Madrasah Aliyah Hidayatullah Mataram Tahun Ajaran 2021/2022 yang berjumlah 55 siswa. Adapun sampel dalam penelitian ini adalah salah Dengan begitu, maka pemilihan kelas kontrol dan kelas eksperimen dilakukan menggunakan teknik Random Sampling dengan menggunakan koin yang dimana lambang garuda dijadikan sebagai simbol kelas eksperimen dan lambang bunga sebagai kelas kontrol. Dari hasil pelemparan koin tersebut didapat kelas X A Madrasah Aliyah Hidayatullah Mataram Tahun Ajaran 2021/2022 yang berjumlah 24 siswa sebagai kelompok eksperimen dan kelas X B Madrasah Aliyah Hidayatullah Mataram Tahun Ajaran 2021/2022 yang berjumlah 24 siswa sebagai kelompok kontrol, dimana kelas eksperimen adalah kelas yang belajarnya menggunakan metode demonstarsi, sedangkan kelas kontrol adalah kelas yang belajarnya menggunakan pembelajaranbiasa yang digunakan oleh guru.

Instrumen dan teknik pengumpulan data yang digunakan adalah berupa angket dan dokumentasi. Teknik analisis data dalam penelitian kualitatif adalah bersifat induktif, yaitu suatu analisis berdasarkan data yang diperoleh, selanjutnya dikembangkan pola hubungan tertentu atau menjadi hipotesis. Adapun rumus yang digunakan dalam penelitian ini adalah sebagai berikut:

$x^{2}=\sum\left[\frac{\left(f_{o-} f_{h}\right)^{2}}{f_{h}}\right]$

(Arikunto, 2010)

Keterangan:

$x^{2}=$ Chi-kuadrat

$f_{0}=$ Frekuensi yang diobservasi

$f_{h}=$ Frekuensi yang diharapkan

Adapun langkah-langkah yang di tempuh dalam menganalisis data pada penelitian ini sebagai berikut:

1. Merumuskan hipotesis nol (Ho)

2. Membuat tabel kerja

3. Memasukkan data ke dalam rumus

4. Menguji nilai hiotesis

5. Menarik kesimpulan

\section{Hasil Penelitian dan Pembahasan}

Sehubungan dengan analisis data yang menggunakan analisis data statistik, sebagai langkah awal dalam menganalisa terlebih dahulu peneliti merumuskan hipotesis nol (Ho) yang berbunyi : "Ada Pengaruh model pembelajaran questioning terhadap motivasi belajar siswa kelas VIII A pada mata pelajaran IPS Terpadu di SMPN 2 Madapangga tahun pelajaran 2018/2019". 
Tabel 1. Membuat Tabel Kerja

\begin{tabular}{|c|c|c|c|}
\hline No & Subjek & Sebelum (fo) & Sesudah (fh) \\
\hline 1 & $\mathrm{P}$ & 52 & 68 \\
\hline 2 & $\mathrm{P}$ & 57 & 58 \\
\hline 3 & $\mathrm{P}$ & 49 & 69 \\
\hline 4 & $\mathrm{P}$ & 51 & 57 \\
\hline 5 & $\mathrm{P}$ & 53 & 65 \\
\hline 6 & $\mathrm{~L}$ & 51 & 65 \\
\hline 7 & $\mathrm{~L}$ & 50 & 58 \\
\hline 8 & $\mathrm{~L}$ & 48 & 58 \\
\hline 9 & $\mathrm{~L}$ & 54 & 59 \\
\hline 10 & $\mathrm{~L}$ & 52 & 65 \\
\hline 11 & $\mathrm{~L}$ & 55 & 60 \\
\hline 12 & $\mathrm{P}$ & 49 & 60 \\
\hline 13 & $\mathrm{~L}$ & 51 & 60 \\
\hline 14 & $\mathrm{~L}$ & 54 & 61 \\
\hline 15 & $\mathrm{P}$ & 48 & 70 \\
\hline 16 & $\mathrm{~L}$ & 54 & 63 \\
\hline 17 & $\mathrm{P}$ & 50 & 66 \\
\hline 18 & $\mathrm{~L}$ & 51 & 55 \\
\hline 19 & $\mathrm{~L}$ & 58 & 63 \\
\hline 20 & $\mathrm{P}$ & 60 & 78 \\
\hline 21 & $\mathrm{~L}$ & 52 & 66 \\
\hline 22 & $\mathrm{~L}$ & 59 & 63 \\
\hline 23 & $\mathrm{~L}$ & 49 & 63 \\
\hline 24 & $\mathrm{~L}$ & 55 & 62 \\
\hline $\mathbf{J m l}$ & & 1.261 & 1.512 \\
\hline
\end{tabular}

Selanjutnya, data tabulasi angket d1atas, dirumuskan kedalam tabel kerja. Sebelum merumuskan tabel kerja tersebut, peneliti membuat interval kategori pada hasil data angket sebelum (fo) dan sesudah (fh) dengan langkah-langkah sebagai berikut :

$$
\frac{k}{i}=10 \rightarrow 20
$$

Keterangan : $\mathrm{i}=$ Interval class

$\mathrm{R}$ = Range

Sedangkan mencari range $(\mathrm{R})$ dengan menggunakan rumus :

$\mathrm{R} \quad=\mathrm{H}-\mathrm{L}+1$

Keterangan: $\quad \mathrm{H}=$ Skor nilai tertinggi

$\mathrm{L}=$ Skor nilai terendah

1 = Bilangan konstan

Perhitungan interval pada jumlah dari hasil tabulasi angket sebelum (fo) menggunakan metode pembelajaran Questioning

$\mathrm{R}=\mathrm{H}-\mathrm{L}+1$

$\mathrm{R}=60-48+1$

$=13$

$\mathrm{i}=\frac{13}{3}=4,3$

Perhitungan interval pada jumlah dari hasil tabulasi angket sesudah (fh) menggunakan metode pembelajaran demonstrasi : 
$\mathrm{R}=\mathrm{H}-\mathrm{L}+1$

$\mathrm{R}=78-55+1$

$=24$

$\mathrm{i}=\frac{24}{3}=8$

Dari hasil diatas, tabel interval yang diperoleh dari nilai terendah hingga tertinggi adalah 4 dan 8 pada masing-masing jumlah tabulasi hasil angket sebelum (fo) dan sesudah (fh) menggunakan metode pembelajaran demontrasi. Dari hasil tersebut dapat dirumuskan tabel dengan kelipatan 3 untuk mengkategorikannya adalah sebagai berikut:

Tabel 2. kategori Sebelum Perlakuan (fo)

\begin{tabular}{ccccc}
\hline \multirow{2}{*}{ Interval } & \multirow{2}{*}{ Kategori } & \multicolumn{2}{c}{ Subyek } & \multirow{2}{*}{ Jumlah } \\
\cline { 3 - 4 } & & $\mathbf{L}$ & $\mathbf{P}$ & \\
\hline $60-66$ & Tinggi & 0 & 1 & 1 \\
\hline $54-59$ & Sedang & 7 & 1 & 8 \\
\hline $48-53$ & Rendah & 8 & 7 & 15 \\
\hline Tabel 3. kategori Sesudah Perlakuan (fh) \\
\hline Interval & Kategori & Subyek & Jumlah \\
\cline { 1 - 3 } & & $\mathbf{L}$ & $\mathbf{P}$ & \\
\hline $70-78$ & Tinggi & 0 & 2 & 2 \\
\hline $64-69$ & Sedang & 3 & 4 & 7 \\
\hline $55-63$ & Rendah & 12 & 3 & 15 \\
\hline
\end{tabular}

Berdasarkan data hasil tabulasi angket di atas, maka tabel kerja perhitungan nilai chi-kuadrat dapat dilihat pada tabel berikut ini:

Tabel 4. Perhitungan nilai chikuadrat

\begin{tabular}{lccccc}
\hline Kategori & Fo & Fh & fo-fh & (fo-fh)2 & $\frac{\text { (fo-th) }}{\text { fh }}$ \\
\hline Tinggi & 1 & 2 & -1 & 1 & 0.50 \\
Sedang & 8 & 7 & 1 & 1 & 0.11 \\
Rendah & 15 & 15 & 0 & 0 & 0 \\
Jumlah & & & & & $\mathbf{0 . 6 1}$ \\
\hline
\end{tabular}

\section{Memasukan Data Kedalam Rumus}

Sesuai dengan data yang telah diolah di atas, maka dapat ditetapkan besarnya nilai hitung Chi-Kudrat $\left(\boldsymbol{x}^{2}\right)$ sebagai berikut:

$$
x^{2}=\Sigma\left[\frac{\left.\mathrm{f}_{\mathrm{i}}-\mathrm{f}_{\mathrm{h}}\right)^{2}}{\mathrm{f}_{\mathrm{h}}}\right] \text { yaitu }=\mathbf{0 . 6 1}
$$

Setelah $x^{2}$ diperoleh yaitu sebesar 0,61 , maka langkah berikutnya adalah menguji nilai $x^{2}$ dengan terlebih dahulu menetapkan besarnya Nilai hitung derajat chi-kuadrat sebagai berikut: Df $=(b-1)(k-1)$

Keterangan:

$\mathrm{b}=$ jumlah baris dalam tabel

$\mathrm{k}=$ jumlah kolom dalam tabel

Menguji Taraf Signifikansi

Berdasarkan tabulasi data pada tabel 4 dengan Df $=(\mathrm{b}-1)(\mathrm{k}-1)$ di atas, maka tabel yang digunakan adalah $2 \times 3$, di mana tabel tersebut mempunyai baris sebanyak 2 dan kolom sebanyak 3. Maka df yang diperoleh adalah: $(2-1)(3-1)=2$. Berdasarkan taraf signifikansi 
$5 \%$ dan $\mathrm{df}=3$, ternyata besarnya angka batas penolakan ( Ho ) yang ditunjukkan pada tabel sebesar 15,507 , Sedangkan nilai $x^{2}$ yang diperoleh 0,61

\section{Menarik Kesimpulan}

Dari hasil uji chi square menunjukan nilai chi hitung sebebsar 0,61 maka berdasarka taraf signifikansi $5 \%$ dan $\mathrm{db}=3$ ternyata besarnya angka penolakan hipotesis nol yang dinyatakan dalam tabel distribusi adalah 0,61 . Kenyataan ini menunjukan bahwa nilai chi hitung lebih kecil dari pada nilai chi tabel $(0,61<15,507)$, karena chi hitung lebih kecil dari chi tabel. Hasil penelitian ini menunjukkan bahwa hipotesis nol (Ho) diterima dan hipotesis alternatif (Ha) ditolak yang berarti penelitian ini tidak signifikan, maka kesimpulan analisis datanya dapat dilihat pada tabel 4.6 sebagai berikut:

Tabel 5. Hasil Analisis

\begin{tabular}{|c|c|c|c|c|c|}
\hline No & Variabel & Nilai $x^{2}$ Hitung & Nilai $x^{2}$ Tabel & Hipotesis Nol (Ho) & $\begin{array}{l}\text { Hipotesis } \\
\text { Alternatif (Ha) }\end{array}$ \\
\hline 1 & $\begin{array}{l}\text { Model } \\
\text { Pembelaja } \\
\text { ran } \\
\text { demontras } \\
\text { i terhadap } \\
\text { hasil } \\
\text { belajar } \\
\text { siswa }\end{array}$ & 0,61 & 15,507 & Diterima & Ditolak \\
\hline
\end{tabular}

Berdasarkan tabel di atas, dapat disimpulkan bahwa: hipotesis nol (Ho): ada Pengaruh Metode Pembelajaran Demonstrasi Terhadap Hasil Belajar Siswa Kelas X Mata Pelajaran Fiqih Di Madrasah Aliyah Hidayatullah Mataram Tahun Pelajaran 2020/2021 "diterima" dan hipotesis alternatif (Ha) yang berbunyi: Tidak ada Pengaruh Metode Pembelajaran Demonstrasi Terhadap Hasil Belajar Siswa Kelas X Mata Pelajaran Fiqih Di Madrasah Aliyah Hidayatullah Mataram Tahun Pelajaran 2020/2021 “ditolak”.

\section{Pembahasan}

Berdasarkan hipotesis yang diajukan atau dugaan yang disusun berdasarkan teori maupun asumsi, ternyata dapat dibuktikan secara empiris. Dengan demikian hasil penelitian ini dapat membuktikan bahwa Model Pembelajaran Questioning ada pengaruh terhadap motivasi belajar siswa. Berdasarkan landasan teori yang diajukan, dibandingkan dengan analisis data yang diperoleh melalui penelitian dengan menggunakan analisis statistik dengan rumus chi square, ternyata hipotesis nol (Ho) yang berbunyi: ada Pengaruh Metode Pembelajaran Demonstrasi Terhadap Hasil Belajar Siswa Kelas X Mata Pelajaran Fiqih Di Madrasah Aliyah Hidayatullah Mataram Tahun Pelajaran 2020/2021 diterima, dan Hipotesis alternatif (Ha) yang berbunyi: Tidak ada Pengaruh Metode Pembelajaran Demonstrasi Terhadap Hasil Belajar Siswa Kelas X Mata Pelajaran Fiqih Di Madrasah Aliyah Hidayatullah Mataram Tahun Pelajaran 2020/2021ditolak. , karena nilai hitung lebih kecil daripada nilai tabel $(0,61<15,507)$. Berdasarkan pembahasan di atas, adapun alasan ataupun pendapat peneliti kenapa (Ho) diterima :

1. Kesalahan pengambilan sampel

2. Kesalahan input data

3. Kesalahan teknik analisis

4. Kesalahan dalam menerima hipotesis 


\section{Kesimpulan}

Berdasarkan hasil penelitian dan pembahasan maka dapat disimpulkan bahwa "terdapat Pengaruh Metode Pembelajara Demontrasi Terhadap Hasil Belajar Siswa Kelas X Mata Pelajaran Fiqih di Madrasah Aliyah Hidayatullah Mataram Tahun Pelajaran 2021/2022 diterima, dan Hipotesis alternatif (Ha) yang berbunyi: Tidak ada Pengaruh Metode Pembelajara Demontrasi Terhadap Hasil Belajar Siswa Kelas X Mata Pelajaran Fiqih di Madrasah Aliyah Hidayatullah Mataram Tahun Pelajaran 2021/2022, karena nilai hitung lebih kecil daripada nilai tabel $(0,61<15,507)$.

\section{Saran}

Adapun saran pada penelitian ini ditujukan kepada kepada: (1) Kepala sekolah, hendaknya selalumemberikan motivasi kepada guru bidang studi, wali kelas, dan pihak-pihak lainnya dalam penggunaan strategi pembelajarann yang bervariasi agar hasil belajar siswa lebih baik.

(2) Kepada guru hendaknya dalam pembelajaran bahasa Indonesia untuk dapat menggunakan strategi pembelajaran yang sehingga dapat meningkatakn hasil belajar bagi siswa.

\section{Daftar Pustaka}

Bisri, Cik Hasan. (2015). Model Penelitian Fiqih, Jakarta: Prenada Media.

Daradjat, Zakiyah. (2004). Metodik Khusus Pengajaran Agama Islam. Jakarta: Bumi Aksara.

Departemen Agama RI. (2015). Al-Qur'anul Karim Mushaf Terjemah An-Nisa'. Jakarta: Tim Falakhusna.

Djazuli. (2006). Ilmu Fiqih: Penggalian, Perkembangan, dan Penerapan Hukum Islam. Jakarta: Kencana.

Irma Listianti. (2014). Pengaruh Metode Demonstrasi Terhadap Hasil Belajar Pada Materi Jama' Qasar Kelas VII di MTs Negeri Tunggangri Tulungagung Tahun 2013/2014. STAIN Tulungagung: Skripsi Tidak Diterbitkan.

Kasiram Moh. (2015). Metode Penelitian Kualitatif-Kuantitatif. Malang: UIN Maliki Press.

Kementrian Agama RI. (2011). Al-Qur'an dan Terjemahnya. Jakarta: PT. Adhi Aksara Abadi Indonesia.

Maunah, Binti. (2019). Landasan Pendidikan. Yogyakarta: Teras.

Munardji. (2015). Ilmu Pendidikan Islam. Jakarta Pusat: Bina Ilmu.

Mustaqim. (2001). Psikologi Pendidikan. Yogyakarta: Fakultas Tarbiyah IAIN Walisongo Semarang.

Nata, Abuddin. (2016). Perspektif Islam tentang Strategi Pembelajaran. Jakarta: Kencana.

Nazarudin, Mgs. (2016). Manajemen Pembelajaran. Yogyakarta: Teras.

Oemar, Hamalik. (2015). Kurikulum dan Pembelajaran. Jakarta: Bumi Aksara

Ridwan, Abdullah Sani. (2014). Inovasi Pembelajaran. Jakarta: Bumi Aksara.

Siti Ma'rifatul Muyasaroh. (2013). Penerapan Metode Demonstrasi Pada Mata Pelajaran Fiqih di MTs Negeri Karangrejo Tulungagung Tahun 2012/2013. STAIN Tulungagung: Skripsi Tidak Diterbitkan.

Wiwin Dwi Wahyuningtyas. (2012). Peningkatan Hasil Belajar Fiqih Melalui Penerapan Metode Demonstrasi Siswa Kelas III di MI Negeri Rejotangan Tulungagung. STAIN Tulungagung: Proposal Tidak Diterbitkan.

Yuwono, Ipung. (2017). Pembelajaran Secara Membumi. Malang: IKIP Malang. 